\title{
Autoimmune Mimicry Face of Wilson's Disease
}

\author{
Tanya Petcova, Krasimir Antonov, Rosen Nikolov, Zoia \\ Spasova, Lyudmila Mateva
}

University Hospital "St. Ivan Rilski" Sofia, Clinic of

\begin{abstract}
Wilson's disease is an autosomal recessive disorder. It results in the accumulation of copper in the liver, brain, and other organs. An impairment in the biliary excretion process leads to copper accumulation in the liver, which progressively damages the liver, leading to cirrhosis. Wilson's disease is characterised by low serum ceruloplasmin levels, low copper levels, Kayser-Fleischer rings, and hypercupriuria. Case Description: we describe the case of a young female who did not have classical features for Wilson's disease. She presented with hepato-splenomegaly, elevated aminotransferase levels, increased serum immunoglobulin IgG, detectable antinuclear antibodies and anti-smooth muscle antibodies. On this basis the diagnosis autoimmune hepatitis was set. In spite of the conducted immunosuppressive therapy with Imuran - $100 \mathrm{mg} / \mathrm{d}$ and Dehydrocortison $20 \mathrm{mg} / \mathrm{d}$ for about 4 months, an improvement wasn't observed. The disease deteriorated with a progression to liver cirrhosis. So another explanation for the disease had to be found. Conclusions: The clinical presentation of Wilson disease is extremely variable and may mimic autoimmune hepatitis. Untreated Wilson's disease is usually fatal, with most patients dying from liver disease, and a minority from progressive neurologic complications. Chelation treatment and liver transplantation prolong survival to normal.
\end{abstract}

Keywords: Wilson disease, autoimmune hepatitis, chelation treatment, Kayser-Fleischer rings

\section{Background}

Wilson's disease is a genetic disorder due to mutation in ATP 7B gene on chromosome 13 that results in impaired copper excretion by the liver. Patients may present with severe chronic liver disease, with hepatosplenomegaly, ascites, a low serum albumin level and persistently abnormal coagulation test results. Some patients have isolated splenomegaly only. Wilson's disease can be represented as liver 
steatosis or autoimmune hepatitis (especially in young women) and can be combined with chronic HBV or $\mathrm{HCV}$ infections.

\section{Case Description}

We present a clinical case of a 44 years old woman, who presented with fatigue, itching, increased AST and ALT, hepatomegaly and splenomegaly in 2007. Viral etiology was excluded in November, 2008 (HBsAg (-)neg, anti-HCV (-)neg).

Table 1. Dynamics of immunological tests and clinical symptoms

\begin{tabular}{|c|c|c|c|c|c|c|c|c|}
\hline DATE & ALT & ANA & ASMA & AMA & ANCA & IgG & IgM & IgA \\
\hline 2008 & 100 & $\begin{array}{c}1: 160 \\
(1: 20)\end{array}$ & $\begin{array}{c}1: 80 \\
(1: 40)\end{array}$ & Neg & $\begin{array}{c}1: 80 \\
(1: 10)\end{array}$ & $\begin{array}{c}32 \mathrm{~g} / \mathrm{l} \\
(5-18)\end{array}$ & $\begin{array}{c}3,4 \mathrm{~g} / \mathrm{l} \\
(3-5)\end{array}$ & $\begin{array}{c}3,4 \mathrm{~g} / \mathrm{l} \\
(3-5)\end{array}$ \\
\hline \multicolumn{7}{|c|}{ Dec 2008 - Started Imuran 100 mg per day; Dehydrocortison 20 mg per day } \\
\hline 2009 & 111 & $1: 80$ & $1: 40$ & Neg & Neg & $17,5 \mathrm{~g} / \mathrm{l}$ & $3,06 \mathrm{~g} / \mathrm{l}$ & $2,5 / \mathrm{I}$ \\
\hline
\end{tabular}

The diagnosis autoimmune hepatitis was set. Treatment with Azatioprin $100 \mathrm{mg} / \mathrm{d}$ and Dehydrocortison 20 $\mathrm{mg} / \mathrm{d}$ was initiated in December 2008. Despite the immunosuppressive treatment a clinical recovery was not seen. A disease progression was determined - formation of liver cirrhosis, which implied searching for another reason for the disease. In March 2009, there were laboratory data for low ceruloplasmin $0.1 \mathrm{mg} / \mathrm{l}$ (normal values $0,1-1 \mathrm{mg} / \mathrm{l}$ ), higher 24-hour urinary copper excretion of $8.4 \mu \mathrm{mol} / \mathrm{l}$ (normal values $<1,6$ $\mu \mathrm{mol} / 24 \mathrm{~h}$ ) and a Kaiser-Fleischer ring was found, due to copper deposition in the cornea (Descemet's membrane). Usually, the combination of Kayser-Fleischer ring and a low serum ceruloplasmin $(<0.1 \mathrm{~g} / \mathrm{L})$ level is sufficient to establish the diagnosis. In our patient the presence of a dual heterozygote $\mathrm{H} 1069 \mathrm{Q} / \mathrm{R} 616 \mathrm{Q}$ was found additionally in June 2009.

In August 2009, the patient presented with fatigue, malaise, increased weight with 7-8 kg, with icteric conjunctiva and skin and limb oedema. There was a moderate ascites. At that time laboratory findings revealed a slight anemia, low platelet count, increased total bilirubine, hypoalbuminemia, prolonged PT. Ultrasonography proved a liver cirrhosis and ascites. Treatment with D -Peicillamine - $500 \mathrm{mg} / \mathrm{d}$ was commenced which led to severe leucopenia (leuco 1,8 G/l). After D-Penicillamine withdrawal, leucocyte number returned to normal. The drug was started again in October 2009 at a dose of $500 \mathrm{mg} / \mathrm{d}$ and later Dehydrocortison $10 \mathrm{mg} / \mathrm{d}$ was added. A significant improvement was seen in April 2010. At that time due to normal levels of bilirubin and albumin, with no ascites, Dehydrocortison was stopped. A dose of 1000 $\mathrm{mg} / \mathrm{d}$ D- Penicillamine was reached in February 2013. The liver cirrhosis was compensated and fibrogastroscopy revealed oesophageal varices grade 2 . 
Table 2. Dynamics of clinical symptoms and laboratory tests

\begin{tabular}{|c|c|c|c|c|c|c|c|}
\hline Date & AST & ALT & $\begin{array}{l}\text { T/D } \\
\text { BIL }\end{array}$ & INR & ALB & $\mathrm{Hg}$ & Ascites \\
\hline August, 2009 & 99 & 65 & $79 / 46$ & 1,76 & 27 & 118 & Yes \\
\hline \multicolumn{8}{|c|}{$\begin{array}{c}\text { Start of D- Penicillamine treatment with } 500 \mathrm{mg} \text { per day } \\
\text { Dehydrocortison } 20 \mathrm{mg}\end{array}$} \\
\hline October 2009 & 117 & 70 & $61 / 28$ & 1,8 & 29 & 107 & No \\
\hline April 2010 & 49 & 35 & $26 / 11$ & 1,35 & 37 & 127 & No \\
\hline \multicolumn{8}{|c|}{$\begin{array}{c}\text { Stop of Dehydrocortison } 20 \mathrm{mg} \\
\text { Continuation of D- Penicillamine treatment } 500 \mathrm{mg} \text { per day }\end{array}$} \\
\hline March 2011 & 44 & 41 & $27 / 4,0$ & 1,27 & 42 & 132 & No \\
\hline January 2013 & 37 & 36 & $22 / 5,0$ & 1,3 & 44 & 125 & No \\
\hline August 2014 & 35 & 28 & $27 / 8,0$ & 1,2 & 47 & 133 & No \\
\hline
\end{tabular}

\section{Decision and Conclusion}

The clinical presentation of Wilson disease is extremely variable. The age of onset of symptoms is even broader, ranging from 3 to 55 years. In 40 to $50 \%$ of individuals with Wilson's disease, hepatic dysfunction is the initial clinical manifestation (1). Hepatic dysfunction in Wilson's disease may assume several forms. Asymptomatic enlargement of the liver and spleen may occur, sometimes with elevation of liver enzymes. It may also present as fulminant hepatic failure, with severe coagulopathy and encephalopathy. Acute intravascular hemolysis is usually present, and renal failure may develop (6). The hepatic symptoms of Wilson's disease may also mimic autoimmune hepatitis (2). In this setting ceruloplasmin, as an acutephase reactant, may rise transiently to normal range. Wilson disease may present in children and young adults as a disease indistinguishable from autoimmune hepatitis. Autoimmune hepatitis may present with fatigue, malaise, arthropathy, and rashes; laboratory findings include elevated aminotransferase levels, increased serum immunoglobulin (lgG) concentration, and detectable nonspecific autoantibodies such as antinuclear antibodies and anti-smooth muscle antibodies $(3,4,5)$. At this setting Wilson disease must be specifically excluded because the treatment of the two diseases is entirely different. The H1069Q mutation, which is the most frequent mutation in the United States and northern Europe, has been reported to be associated with later onset of symptoms and less severe disruption of copper metabolism, although not all studies support this assertion $(7,8,9)$. With appropriate treatment, the long-term prognosis for patients with Wilson's disease, mimicking autoimmune hepatitis, appears to be favorable, even if cirrhosis is present. The most frequent mode of hepatic presentation of Wilson's disease, however, is the development of progressive cirrhosis, which has no specific features for Wilson's disease. Due to the variable hepatic presentation of Wilson's disease, in every individual under 50 years, with unexplained liver disease, this diagnosis should be excluded. Patients with early hepatic disease have a generally favorable prognosis, as long as treatment is consistent and well tolerated. Still, severe neurologic disease may not resolve entirely during treatment.

\section{References}

1. EASL Clinical Practice Guidelines: Wilson's disease 2012; 56: 671-685. 
2. Feldman M, Friedman L, Brandt L. Sleisenger and Fordtran's Gastointestinal and liver disease 2010; 75:1251-1254.

3. Milkiewicz P, Saksena S, Hubscher SG, et al. Wilson's disease with superimposed autoimmune features: report of two cases and review. J Gastroenterol Hepatol 2000;15:5:570-574.

4. Nikias GA, Batts KP, Czaja AJ. The nature and prognostic implications of autoimmune hepatitis with an acute presentation. J Hepatol 1994;5:866-871.

5. Crapper RM, Bhathal PS, Mackay IR, et al.'Acute' autoimmune hepatitis. Digestion 1986;34:3:216225.

6. Korman JD, Volenberg I, Balko J, et al. Screening for Wilson disease in acute liver failure: a comparison of currently available diagnostic tests. Hepatology 2008; 48:1167-1174.

7. Gromadzka G, Schmidt HH, Genschel J, et al. p.H1069Q mutation in ATP7B and biochemical parameters of copper metabolism and clinical manifestation of Wilson's disease. Mov Disord 2006; $21245-248$.

8. Vrabelova S, Letocha $\mathrm{O}$, Borsky $\mathrm{M}$, et al. Mutation analysis of the ATP7B gene and genotype/phenotype correlation in 227 patients with Wilson disease. Mol Genet Metab 2005;86:277-285.

9. Ferenci P, Caca K, Loudianos G, et al. Diagnosis and phenotypic classification of wilson disease. Liver Int 2003;23:139-142.

\title{
Corresponding author
}

\author{
Tanya Petcova, MD \\ Clinic of Gastroenterology, \\ St "Ivan Rilski " University Hospital \\ 15 Acad. Ivan Geshov Blvd \\ Sofia 1431 \\ Bulgaria \\ e-mail:petcovatanya@gmail.com \\ fax: + 35928510816
}

